\title{
Maternal and fetal complications during pregnancy and puerperium in obese women
}

\author{
Mrudula Munibala, Veena KS \\ Corresponding author: Dr. Veena KS, Associate Professor, Department of Obstetrics and \\ Gynecology, Sri Manakula Vinayagar Medical College and Hospital, Madagadipet, Pondicherry, \\ India; Email : ssykid2003@yahoo.co.uk
}

Distributed under Attribution-Non Commercial - Share Alike 4.0 International (CC BY-NC-SA 4.0)

\begin{abstract}
Background: The magnitude of prevalence of obesity has been increasing in developing nations. Obesity poses risk of cardiovascular and metabolic problems for the woman and her offspring. There is paucity of data regarding complications among obese pregnant women in India, hence this study was conducted. Objectives: To assess complications associated during pregnancy, labor, puerperium and immediate effect on new born among obese women. Methodology: 110 pregnant women attending antenatal clinic in first trimester were enrolled and grouped into obese and non-obese based on BMI. Patients were observed for development of gestational hypertension, preeclampsia, GDM, mode of delivery and puerperial infection. Fetal outcome was documented in terms of APGAR scores, birth weight, NICU admission and compared between two groups. Results: Incidence of gestational diabetes was $14 \%$ and $2 \%$, gestational hypertension was $8 \%$ and $0 \%$, preeclampsia was $16 \%$ and $4 \%$ in obese and control groups respectively which were statistically significant. Obese women had 3.14 times increased risk of being induced than controls. The primary caesarean delivery rates were higher in obese group (36\%) compared to controls $(16 \%)$. Wound infection and wound dehiscence rates were higher in the obese women $(10 \%$ and $4 \%)$ than the controls $(2 \%$ and $2 \%$ ). Mean birth weight of the neonate in the obese group was $3.16 \mathrm{~kg}$ and $2.87 \mathrm{~kg}$ in the controls which was statistically significant. Conclusion: Obesity during pregnancy has risk of developing hypertension, diabetes, induction of labor, LSCS, wound infection, delivering large babies and neonatal admissions. We recommend counseling of pregnant women to prevent such complication.
\end{abstract}

Keywords: Obesity, macrosomia, preeclampsia, gestational diabetes, wound infection, labor induction.

Obesity is fast growing problem worldwide. As per WHO data the worldwide prevalence of obesity nearly tripled between 1975 and $2016^{1}$. Previously, developed countries were facing the burden of obesity related health problems however now developing countries are also experiencing a rapid increase in non-communicable disease due to rise in obesity. According to National Family Health Survey of India in 2016, women who are overweight or obese (BMI $\geq 25.0 \mathrm{~kg} / \mathrm{m} 2)$ are $20.6 \%$ against $12.6 \%$ in 2005 $06 .^{2}$ It becomes a major issue when it affects the women of reproductive age group, as obesity makes a pregnancy high risk by the increased incidence of gestation diabetes, preeclampsia, labor induction, increased caesarean rates, post-operative morbidity, prolonged hospital stay, venous thromboembolism, anesthetic complications etc. Genetics, childhood obesity, PCOD (polycystic ovarian disease), previous pregnancy weight gain, ethnicity, eating habits are blamed for prepregnancy obesity. Complications can be minimized by life style modification and proper diet plan. Obese mothers are at increased risk of delivering babies with congenital anomalies, stillbirth, prematurity, macrosomia and increased risk of NICU (neonatal intensive care unit) admissions. In utero exposure to maternal obesity is associated with an increased risk of developing obesity and

Received: $2^{\text {nd }}$ August 2020, Peer review completed: $29^{\text {th }}$ October 2020, Accepted:

Munibala M, Veena KS. Maternal and fetal complications during pregnancy and puerperium in obese women. The New Indian Journal of OBGYN. 2021; 8(1): 69-74. 
metabolic disorders in childhood.

Currently WHO classified women with BMI of 18.5-24.9 $\mathrm{kg} / \mathrm{m} 2$ as normal, $25.0-29.9 \mathrm{~kg} / \mathrm{m} 2$ as overweight and $\geq 30$ $\mathrm{kg} / \mathrm{m} 2$ as obese. Although routine weighing of pregnant women is carried out in antenatal clinics, not much importance is given to the weight of the women as such. Most of the prospective studies among obese pregnant women are conducted in western population and less data is available among Indian women. Hence this cohort study was conducted at our hospital.

Our study aims at finding out the incidence of complications due to maternal obesity and to assess the neonatal and obstetric outcomes. Results of our study will help clinicians in predicting the complications of obesity during the pregnancy and also to educate women regarding obesity and its preventable complication.

\section{Methodology}

This was a prospective cohort study conducted at the department of obstetrics \& gynecology in a tertiary hospital, Pondicherry for a period of 24 months, from June 2016 to May 2018. Pregnant women who visited hospital in first trimester were considered for the study. Women were divided in to two groups. Group one with BMI $<25 \mathrm{~kg} / \mathrm{m} 2$ and the group two with $\mathrm{BMI} \geq 30 \mathrm{~kg} / \mathrm{m} 2$ were matched for gestational age and parity. Approval by institutional ethics committee was obtained. Informed consent was taken from all the participants of the study. Mothers who booked after 12 weeks, who lost in follow up were excluded from study.

Pregnant mothers attending the antenatal OPD in their first trimester were selected according to the inclusion criteria and a detailed history was taken with complete general and physical examination was done. Relevant hematological and biochemical investigations and ultrasound examination were done. They were followed up till the delivery and the postpartum period until discharge. They were carefully monitored for gestational diabetes mellitus (GDM), pre-eclampsia, gestational hypertension, labor induction and their indication, mode of delivery, shoulder dystocia, instrumental delivery, postpartum hemorrhage $(\mathrm{PPH})$, deep vein thrombosis (DVT), postoperative wound infection, postoperative wound dehiscence and duration of hospital stay. In new born babies, gestational age at birth, birth weight, Apgar at 1 and 5 minutes duration and indications of NICU admissions were analyzed. The rates of pregnancy complications and the maternal and fetal outcomes detected were compared between the two groups and their differences were evaluated using chi- square and student $t$ test. Statistical significance was deemed at a $p$ value of $<0.05$. Odd's ratio was calculated expressing the relationship between obesity group and specific maternal outcomes.

\section{Results}

55 pregnant women with BMI $>30 \mathrm{~kg} / \mathrm{m} 2$ and 55 pregnant women with BMI 18.5- $25 \mathrm{~kg} / \mathrm{m} 2$ were selected and followed up prospectively. 5 patients from obese group and 5 patients from control group were lost in follow up. 100 patients were included in data analysis.

$40 \%$ of obese group women were aged between $25-29$ years. Whereas $48 \%$ of control group women were between $20-24$ years. The proportion of women in the age group $>30$ years were also higher in the obese group $(26 \%)$ in obese group compared to $18 \%$ in control group. The difference in age group distribution was not statistically significant $(\mathrm{P}=0.43)$. The mean age in obese group was 26.3 years where as in control group it was 25.9 years.

Maternal weight at booking and delivery is summarized in table 1 . Mean weight gain in obese group was $10 \mathrm{~kg}$ where as in control group it was $9.5 \mathrm{~kg}$.

\section{Table 1: Maternal weight}

\begin{tabular}{lllllll}
\hline \multirow{2}{*}{ Group } & \multicolumn{6}{c}{ Weight ( in Kgs) } \\
\cline { 2 - 3 } & \multicolumn{2}{l}{ At booking } & & \multicolumn{2}{c}{ At delivery } & \\
\cline { 2 - 3 } \cline { 5 - 6 } & Range & Mean & SD & Range & Mean & SD \\
\hline Obesity group & $60-92$ & 76.6 & 7.9 & $70-101$ & 86.4 & 7.9 \\
Control group & $44-65$ & 52.7 & 5.4 & $51-73$ & 62.4 & 5.4 \\
\hline 'p' value & $<0.0001$ & \multicolumn{4}{c}{$<0.0001$} \\
\hline
\end{tabular}

In the study group $80 \%$ were moderately obese and $20 \%$ were severely obese. None of the obese women were in very severely obese category. Among obese women 36\% were nulliparous and $64 \%$ were parous women, where as in control group $62 \%$ were nulliparous and $38 \%$ were parous women. The difference in weight was statistically significant.

Among obese women $22 \%$ had irregular menstrual pattern where as $6 \%$ of control women had irregular menstrual pattern. In obese women $16 \%$ had infertility where as in control women it was $2 \%$. Two were diabetic in the obese group where as one had diabetes in control group. One woman had hypertension in the obese group. In both the groups, 2 women had hypothyroidism. One in the control group had heart disease and one in study group had asthma. None of these medical disorders were statistically significant.

Antepartum Complications are summarized in table 2: The incidence of gestational diabetes was $14 \%$ and $2 \%$ in the obese and control groups respectively. The incidence of 
preeclampsia was $16 \%$ and $4 \%$ in the obese and the control groups respectively. The incidence of gestational hypertension was $8 \%$ and $0 \%$ in obese and control groups respectively. These were statistically significant.

Table 2: Antepartum complications

\begin{tabular}{|c|c|c|c|c|c|c|}
\hline \multirow[t]{2}{*}{$\begin{array}{l}\text { Antepartum } \\
\text { complications }\end{array}$} & \multicolumn{2}{|c|}{$\begin{array}{l}\text { Obese } \\
\text { cases }\end{array}$} & \multicolumn{2}{|c|}{$\begin{array}{l}\text { Control } \\
\text { cases }\end{array}$} & \multirow[t]{2}{*}{$\begin{array}{l}\text { 'p' } \\
\text { value }\end{array}$} & \multirow[t]{2}{*}{$\begin{array}{l}\text { Odds } \\
\text { Ratio }\end{array}$} \\
\hline & No & $\%$ & No & $\%$ & & \\
\hline GDM & 7 & 14 & 1 & 2 & 0.0297 & 7.98 \\
\hline Pre eclampsia & 8 & 16 & 2 & 4 & 0.0466 & 4.57 \\
\hline $\begin{array}{l}\text { Gestational } \\
\text { hypertension }\end{array}$ & 4 & 8 & - & - & 0.0423 & - \\
\hline Malpresentation & 2 & 4 & 1 & 2 & 0.5 & 2.04 \\
\hline $\mathrm{APH}$ & - & - & - & & - & - \\
\hline Total cases & & & & & & \\
\hline With complications & $19^{*}$ & 38 & 4 & 8 & 0.0121 & 3.76 \\
\hline Without complications & 31 & 62 & 46 & 92 & & \\
\hline
\end{tabular}

15 patients among obese (30\%) and 6 patients among control group (12\%) went for induction of labor. Among total inductions done, majority of inductions in the obese group were for postdates $(26.7 \%)$ and for hypertensive disorders of pregnancy (20\%). In the control group 50\% of inductions were for postdates.

As described in table 3, natural labor was lower in the obese group (48\%) when compared to control group (66\%). The primary caesarean delivery rates were higher in obese group (36\%) when compared to control group (16\%). The repeat caesarean rates were almost the same, $16 \%$ in obese and $14 \%$ in control group.

Table 3: Mode of delivery

\begin{tabular}{lllll}
\hline Mode of delivery & \multicolumn{2}{l}{ Obese cases } & \multicolumn{2}{l}{ Control cases } \\
& No & \% & No & \% \\
\hline Spontaneous vaginal & 24 & 48 & 33 & 66 \\
Primary LSCS & 18 & 36 & 8 & 16 \\
Repeat LSCS & 8 & 16 & 7 & 14 \\
Forceps/ vacuum & - & - & 2 & 4 \\
\hline 'p' value & 0.042 & & & \\
\hline
\end{tabular}

The caesarean delivery rates were higher in obese group (52\%) than the control group (30\%). Obese women had 2.53 fold increased risk of caesarean delivery than the non-obese women. Obese women had 2.95 times higher risk for caesarean delivery than the control women. Among the primary caesarean deliveries, obese women had higher risk of emergency caesarean delivery (30\%, odd's ratio: 2.63 ) than control group (14\%). Similarly obese women had increased risk of elective caesarean delivery $(6 \%$, odd's ratio: 3.12$)$ than control women $(2 \%)$. The major reasons for primary caesarean delivery were fetal distress, cephalopelvic disproportion and failed induction in the obese women. The major reason for primary caesarean delivery in control group was failed induction, fetal distress and malpresentation.

There was 1 patient with traumatic $\mathrm{PPH}$ in both groups and 1 patient with atonic PPH in both groups. No shoulder dystocia or complete perineal tear occurred in either group.

Postpartum complications are summarized in table 4 . Wound infection and wound dehiscence rates were higher in the obese women $(10 \%$ and $4 \%)$ than the control women $(2 \%$ and $2 \%)$ respectively. The rate of postpartum complications was significantly higher in the obese group.

Table 4: Postpartum complications

\begin{tabular}{lllll}
\hline Postpartum complications & \multicolumn{2}{l}{ Obese cases } & \multicolumn{2}{l}{ Control cases } \\
& No & \% & No & \% \\
\hline Wound infection & 5 & 10 & 1 & 2 \\
Wound dehiscence & 2 & 4 & 1 & 2 \\
DVT & - & - & - & - \\
Acute bronchial asthma & 1 & 2 & 1 & 2 \\
Fever & 4 & 8 & - & - \\
Total cases with complications & 12 & 24 & 3 & 6 \\
\hline 'p' value & 0.0251 & & \\
\hline DVT - Deep vein thrombosis & \multicolumn{5}{l}{} \\
\hline
\end{tabular}

All the women in both the groups gave birth to live babies. No still birth or intrauterine death was recorded. One baby in the control group had early neonatal death on day 4 due to severe birth asphyxia. $90 \%$ of obese women and $92 \%$ of control women delivered at term. $10 \%$ of obese women and $8 \%$ of control women delivered preterm. The difference was not statistically significant. $38 \%$ of the neonates born to obese women were between $3 \mathrm{~kg}-3.49 \mathrm{~kg}$ where as $56 \%$ the neonates born to control women were between $2.5 \mathrm{~kg}-2.99$ kg. $20 \%$ of babies born to obese women were between 3.5 $\mathrm{kg}-3.99 \mathrm{~kg}$ when compared to $14 \%$ in the control women. The mean birth weight of the neonate in the obese group was $3.16 \mathrm{~kg}$ while it was $2.87 \mathrm{~kg}$ in the control group. The difference in the mean birth weight was statistically significant. The difference of Apgar scores at 1 minute and 5 minutes between obese and control group was not statistically significant. $32 \%$ of babies born to obese women were admitted in NICU compare to $12 \%$ of babies of control group. The difference was statistically significant. Babies of obese women had 3.45 times increased risk of being admitted in NICU compared to control women.

The major reason for admission of babies to NICU in the obese women was for care of infants of diabetic women $(43.8 \%)$ and in the control group it was for meconium aspiration (33.33\%). Babies of obese women were also admitted for meconium aspiration and birth asphyxia.

Among vaginal delivery group, $62.5 \%$ of obese women and $31.4 \%$ of control women required prolonged hospital stay ( $>2$ days). In caesarean delivery group $65.4 \%$ of obese 
women and $26.7 \%$ of control women required prolonged hospital stay ( $>7$ days).

\section{Discussion}

Obese women were found to have an increased incidence of gestational diabetes (14\%) when compared to normal BMI group (2\%) with OR 7.98 similar to other studies ${ }^{3,4,5}$.

Adiposity has been blamed for elevation of blood pressure during pregnancy but exact mechanism is not known. Hyperlipidemia, hyperinsulinemia and increased leptin levels along with inflammation likely to cause autonomic nervous system disturbances causing elevation of pressure hormones. We found increased risk of preeclampsia $(16 \%)$ in the obese women when compared to the control group (4\%). The frequency of occurrence was a 4.5 times as high as for obese group comparing to control group. It was similar in other studies ${ }^{3,6}$.

We observed that labor induction was 3.4 times common in obese group when compared to control group (30\% Vs. $12 \%$ ), reasons being postdates $(26.7 \%)$ and hypertensive disorders of pregnancy (20\%). Some authors have noted high incidence of postdated pregnancy among obese women which was not significant comparatively in our study ${ }^{7,8}$

Our study demonstrated an increased risk for caesarean delivery among the obese women (52\%) compared to the normal BMI group (30\%). Obese women had 2.53 fold increased risk of caesarean delivery, condition underlying responsible being fetal distress, cephalopelvic disproportion and failed induction in the obese women. The primary caesarean delivery rates were higher among obese group (36\%) when compared to the control group (16\%). We also found that both emergency and elective primary caesarean deliveries were higher in the obese group. Similar results were obtained in several other studies. ${ }^{9-13}$

In our study no instrumental delivery was noted in the obese group. This is in contrast to other studies ${ }^{14}$. This difference may be due to small sample size in our study.

In our study, occurrence of postpartum complication was high among obese women. Wound dehiscence and febrile illness was 4 times common among obese. We did not find any incidence of maternal mortality or thromboembolism in our study but our follow up was only up to day 8 of postpartum. Several authors demonstrated higher risks of post caesarean wound gaping, discharge and occurrence of seroma among the morbidly obese women ${ }^{3,15,16}$, Operative time and blood loss was not noted in our study.

Increasing obesity trends in developing countries put lot of burden on health care system as well as on patients by increasing the number of hospital admission days. Our study demonstrated prolonged hospital stay is 2 times higher in vaginal delivery and 3 times higher in LSCS among obese women.

Obese mothers have tendency to deliver larger babies. Our study demonstrated that mean birth weight of the neonate in the obese group was $3.16 \mathrm{~kg}$ while it was $2.87 \mathrm{~kg}$ in the control group. Insulin resistance in obese women is high which leads to hyperinsulinemia and elevation of blood glucose levels. The mechanisms by which increased adiposity occur in the offspring are not known however excess availability of nutrients to fetus including glucose and triglycerides leading to hyperinsulinemia and acceleration in growth pattern is blamed. HAPO study also stated that maternal BMI is independently associated with excess fetal growth and adiposity. ${ }^{17}$ Some studies have shown obesity is associated with fetal macrosomia. ${ }^{18,19}$ However in our study occurrence of macrosomia was not significant in obese group which was similar to other studies ${ }^{20,21}$.

Weight gains among obese and non-obese groups were similar in our study. IOM recommends that there should be less weight gain for obese women. Some studies have stated higher weight gain is associated with higher incidence of complications ${ }^{22,23}$. We did not study the correlation between weight gain and adverse pregnancy outcome in our study.

In our study, Babies of obese women had 3.45 times increased risk of being admitted in NICU reasons being for glycemic control, fetal distress and meconium aspiration. Soltani et al demonstrated similar results in their study ${ }^{24}$. High incidence of diabetes, birth injuries and labor complications are responsible for fetal conditions.

Limitation of the study - In our study, we followed the recommendations of WHO classification for BMI. However the definition of obesity for Asians states which is $\geq 25$ $\mathrm{Kg} / \mathrm{m}^{2}$ was not followed in our study. Our study was done at single center with small sample size. Large multicentric study is recommended to assess the exact incidence of these complications.

\section{Conclusions}

Obesity during pregnancy place the mother at risk for various complications like hypertension, diabetes, induction of labor, LSCS, wound infection, delivering large babies and neonatal admissions for various reasons. We recommend counseling about these complications to all the obese patients during their pregnancy. Prevention of obesity, preconception counseling for obese women is need of the hour. Public health authorities, policy makers and healthcare 
providers need to consider this issue to bring down obesity related complications.

\section{Conflict of interest: None. Disclaimer: Nil.}

\section{References}

1. WHO. Obesity and overweight [Internet]. Geneva: WHO. 2020. Available from https://www.who.int/newsroom/fact-sheets/detail/obesity-and-overweight.

2. NFHS-4 Fact Sheets For Key Indicators Based On Final Data. Mumbai: IIPS. 2016. Available from http://rchiips. org/nfhs/factsheet_NFHS-4.shtml

3. Dasgupta A, Harichandrakumar KT, Habeebullah S. Pregnancy Outcome among Obese Indians - A Prospective Cohort Study in a Tertiary Care Centre in South India. Int J Sci Stud. 2014; 2(2):13-8.

4. Chu SY, Callaghan WM, Kim SY, Schmid CH, Lau J, England LJ, et al. Maternal Obesity and Risk of Gestational Diabetes Mellitus. Dia Care. 2007; 30 (8):2070-6.

5. Gao X, Yan Y, Xiang S, Zeng G, Liu S, Sha T, et al. The mutual effect of pre-pregnancy body mass index, waist circumference and gestational weight gain on obesity-related adverse pregnancy outcomes: A birth cohort study. PLoS ONE. 2017; 12(6): e0177418.

6. Bhattacharya S, Campbell DM, Liston WA. Effect of Body Mass Index on pregnancy outcomes in nulliparous women delivering singleton babies. BMC Public Health. 2007; 7:168.

7. Usha Kiran TS, Hemmadi S, Bethel J, Evans J. Outcome of pregnancy in a woman with an increased body mass index. BJOG. 2005; 112 (6): 768-72.

8. Prameela HJ, Madhuri S. Obesity in pregnancy: maternal and perinatal outcome. Int J Reprod Contracept Obstet Gynecol. 2017 Jan; 6(1):141-4

9. Kawaita T, Reddy UM, Landy HJ, et al. Indications for primary cesarean delivery relative to body mass index. Am J Obstet Gynecol. 2016; 215(4): 515.e1-9.

10. Lynch CM, Sexton DJ, Hession M, Morrison JJ. Obesity and mode of delivery in primigravid and multigravid women. Am J Perinatol. 2008; 25(3):163-7.

11. Kim SS, Zhu Y, Grantz KL, et al. Obstetric and neonatal risks among obese women without chronic disease. Obstet Gynecol. 2016; 128: 104-12.

12. Scott-Pillai R, Spence D, Cardwell CR, Hunter A, Holmes VA. The impact of body mass index on maternal and neonatal outcomes: a retrospective study in a UK obstetric population, 2004-2011. BJOG. 2013; 120: 932-9.

13. Ovesen P, Rasmussen S, Kesmodel U. Effect of prepregnancy maternal overweight and obesity on pregnancy outcome. Obstet Gynecol. 2011; 118: $305-12$.

14. Rode L, Nilas L, Wojdemann K, Tabor A. Obesityrelated complications in Danish single cephalic term pregnancies. Obstet Gynecol. 2005; 105(3): 537-42.

15. Dias M, Dick A, Reynolds RM, Lahti- Pulkkinen M, Denison FC. Predictors of surgical site skin infection and clinical outcome at caesarean section in the very severely obese: A retrospective cohort study. PLoS ONE. 2019;14(6): e0216157.

16. Alanis MC, Villers MS, Law TL, Steadman EM, Robinson CJ. Complications of cesarean delivery in the massively obese parturient. American Journal of Obstetrics and Gynecology. 2010; 203(3):271.e1-271.e7

17. Catalano PM, McIntyre HD, Cruickshank JK, HAPO Study Cooperative Research Group, et al. The hyperglycemia and adverse pregnancy outcome study: associations of GDM and obesity with pregnancy outcomes. Diabetes Care. 2012; 35(4): 780-6.

18. Yazdani S, Yosofniyapasha Y, Nasab BH, Mojaveri $\mathrm{MH}$, Bouzari Z. Effect of maternal body mass index on pregnancy outcome and newborn weight. BMC Res. Notes. 2012; 5: 34.

19. Vinturache AE, McDonald S, Slater D, Tough S. Perinatal outcomes of maternal overweight and obesity in term infants: a population-based cohort study in Canada. Sci Rep.2015; 5: 9334.

20. Xiao L, Ding G, Vinturache A, Xu J, Ding X, Guo J, et al. Associations of maternal prepregnancy body mass index and gestational weight gain with birth outcomes in Shanghai. China Scientific Reports. 2017; 7: 41073.

21. Fouelifack FY, Fouedjio JH, Fouogue JT, Sando Z, Fouelifa LD, Mbu RE. Associations of body mass index and gestational weight gain with term pregnancy outcomes in urban Cameroon: a retrospective cohort study in a tertiary hospital. BMC Res. Notes. 2015; 8: 806 .

22. Hinkle SN, Sharma AJ, Dietz PM. Gestational weight gain in obese mothers and associations with fetal growth. Am J Clin Nutr. 2010; 92:644-51.

23. Bhavadharini B, Anjana RM, Deepa M, Jayashree G, Nrutya S, Shobana M, et al. Gestational Weight Gain and Pregnancy Outcomes in Relation to Body Mass 
The New Indian Journal of OBGYN. 2021 (July-December);8(1)

Index in Asian Indian Women. Indian $\mathrm{J}$ Endocrinol Metab. 2017; 21(4):588-93.

24. Soltani H, Lipoeto N, Fair FJ, Kilnerl K, Yusrawati Y. Pre-pregnancy body mass index and gestational weight gain and their effects on pregnancy and birth outcomes: a cohort study in West Sumatra, Indonesia. BMC Women's Health. 2017; 17:102
Mrudula Munibala ${ }^{1}$, Veena $\mathrm{KS}^{2}$

${ }^{1}$ ISRO General Hospital, Department of Obstetrics and Gynecology, Sri Harikota, Andhra Pradesh, India; ${ }^{2}$ Associate Professor, Department of Obstetrics and Gynecology, Sri ManakulaVinayagar Medical College and Hospital, Madagadipet, Pondicherry, India. 